\title{
Células cloro en peces teleósteos
}

\author{
Flores Quintana, C. \\ Instituto de Ictiología del Nordeste, Facultad de Ciencias Veterinarias, UNNE, Sargento Cabral 2139, Corrientes \\ (3400), Argentina. E-mail: carolina@vet.unne.edu.ar.
}

\begin{abstract}
Resumen
Flores Quintana, C.: Células cloro en peces teleósteos. Rev. vet. 20: 1, 57-60, 2009. Las células cloro están vinculadas a la captación y excreción de iones monovalentes, fundamentalmente $\mathrm{Na}$ y $\mathrm{Cl}$. La adaptación a diferentes salinidades implica procesos rápidos o lentos de síntesis y destrucción de componentes moleculares que constituyen sistemas de transporte que van acompañados por cambios celulares morfológicos e hiperplásicos. La variabilidad morfológica de las células cloro determinó la clasificación en diferentes subtipos cuyo predominio depende de las características del ambiente.
\end{abstract}

Palabras clave: pez, células cloro, morfología, respuesta osmótica, sitios de transporte.

\begin{abstract}
Flores Quintana, C.: Chloride cells in teleosts fish. Rev. vet. 20: 1, 57-60, 2009. The chloride cells are related to the uptake and excretion of monovalent ions. The adaptation to different salinities involves a quick or slow process of synthesis and destruction of molecular components which form the transport system, accompanied with morphological and hyperplastic cellular changes. The morphological variability of the chloride cells has defined the classification of different subtypes, which predominance depends on the environment's characteristics.
\end{abstract}

Keys words: fish, chloride cells, morphology, osmotic answer, transport sites.

\section{INTRODUCCIÓN}

Los peces son vertebrados acuáticos distribuidos en compleja taxonomía. Los tres grandes grupos existentes (Agnatha, Condrichthyes y Actinopterygii) usan las branquias como sitio primario de respiración acuática. La gran mayoría de ellos viven en ambientes con concentraciones de iones diferentes al de su medio interno, de manera que controlan la osmolaridad interna y determinados valores iónicos a través de mecanismos de osmorregulación y regulación iónica que implican mantener una determinada cantidad de agua y una apropiada concentración de solutos.

Los teleósteos constituyen un gran grupo de peces con esqueleto óseo, donde se ubica la mayoría de los peces comunes y donde están las formas más evolucionadas. Los de agua dulce tienen fluidos hiperosmóticos con respecto al ambiente y los problemas por intercambios osmóticos obligatorios son hinchamiento por entrada de agua y pérdida de sal hacia el medio. El organismo del pez trabaja en la producción de una orina diluida para eliminar el exceso de agua e incorpora iones monovalentes contra gradiente desde el medio externo diluido a través de las branquias ${ }^{20}$. Los teleósteos ma- rinos presentan osmolaridad inferior al agua de mar, lo cual le acarrea dos problemas fundamentales: ganancia pasiva de iones y pérdida osmótica de agua ${ }^{15}$ por lo que poseen mecanismos osmorreguladores especializados en la incorporación de agua y en la excreción activa de sales que involucran estructuras localizadas en epitelio gastrointestinal, branquias y riñón. El proceso de regulación de iones plasmáticos puede ser muy rápido o lento, según envuelva mecanismos ya existentes o a través de procesos de diferenciación ${ }^{17}$.

Si bien existe marcada diferencia anatómica entre grupos de peces, los componentes celulares son semejantes. Entre las numerosas funciones que desempeñan las branquias, su papel en la osmorregulación reviste vital importancia ${ }^{1,4}$. La complejidad funcional de las branquias se refleja en su complejidad morfológica, encontrándose al menos seis o siete tipos celulares diferentes, entre ellos las células cloro. En principio se consideró que el complejo epitelio branquial tenía origen endodérmico, posteriormente fue propuesto el origen ectodérmico y más recientemente se reporta el origen mixto. Se considera que las células cloro, por estar asociadas al estrato más superficial del epitelio branquial derivan del ectodermo. 


\section{CÉLULAS CLORO}

Las células cloro o células ricas en mitocondrias recuerdan a las secretoras de ácido clorhídrico en el estómago ${ }^{24}$. Estudios morfológicos y citoquímicos sugieren su función en estrecha asociación con la entrada de iones. El término de células cloro fue, por mucho tiempo, restricto a peces marinos porque no existían evidencias de participación en el transporte iónico en peces de agua dulce y se describieron como células rudimentarias ${ }^{26}$. Existe el consenso general que son numerosas y secretan iones en peces marinos, en tanto que en peces de agua dulce absorben iones y son escasas. Sin embargo, en situaciones de estrés osmótico pueden proliferar y ocupar el epitelio branquial laminar ${ }^{20}$.

Están presentes en branquias, tegumento, pseudobranquias y sistema olfativo ${ }^{1,11,20}$. En embriones y larvas se detectaron en el epitelio del saco vitelino y el cuerpo, siendo consideradas sitios de regulación iónica durante la fase ontogénica, en ausencia de branquias funcionales ${ }^{10}$. Las primeras células cloro aparecen a pocas horas de la fertilización y poco después de la eclosión ya son totalmente funcionales. En ese momento la regulación principal pasa por las branquias, sugiriendo que en el inicio del desarrollo las branquias privilegian la función de osmorregulación a la respiratoria. Modelos experimentales in vitro, demuestran mecanismos autónomos de diferenciación celular, independientes de los sistemas endocrino y nervioso ${ }^{8}$. La participación de cortisol y prolactina en este proceso y en la estimulación de la actividad $\mathrm{Na}$ K ATPasa en el epitelio opercular fue demostrada en peces adultos ${ }^{6,17}$.

Para algunos autores, las células cloro no están incorporadas en el epitelio de las láminas secundarias, aunque el estrato más profundo retendría la capacidad potencial para diferenciarse en las mismas. La rápida renovación celular durante la aclimatación al agua salada parece estar vinculada a este estrato. En algunas especies se observan distribuidas en ambos epitelios ${ }^{1,3,24}$. Experimentalmente se encontraron significativas alteraciones en el posicionamiento de las células cloro con la incorporación de sustancias al medio acuático, determinando que las células invadan el área respiratoria en la región intermedia del filamento, con engrosamiento epitelial constituyendo una barrera para que las sustancias del medio no lleguen al lecho vascular. También fueron descriptas en la membrana opercular ${ }^{1}$, en la superficie del opérculo y en el epitelio de las aletas pectorales ${ }^{7}$. En algunos adultos también son observadas en el área labial, mandíbula y abdomen ${ }^{27}$. Aparecen cuando los animales son expuestos a aguas con cadmio, considerándose una respuesta general a diversos estresores.

\section{ESTRUCTURA Y ULTRAESTRUCTURA}

Las células cloro son grandes, eosinófilas, ovoides, con citoplasma abundante, núcleo único, ligeramente basófilo y nucléolo evidente ${ }^{21}$. Sin embargo, el polimorfismo de las células cloro fue demostrado en epite- lio branquial de teleósteos de agua dulce, sugiriéndose cambios en relación directa con la entrada de diversos iones como $\mathrm{Na}, \mathrm{Cl}$ y Ca ${ }^{18}$, en relación a la posición ${ }^{24}$ así como en la regulación ácido-base ${ }^{12,19}$.

Están netamente polarizadas, con membranas apical y basolateral morfológicamente diferentes. La superficie lateral presenta complejos de unión y desmosomas con las epiteliales adyacentes y la membrana apical hace protrusión sobre las células pavimentosas y presenta microvellosidades o microondulaciones en peces de agua dulce ${ }^{24}$. Muestran grandes mitocondrias, extenso sistema tubular membranoso, pequeño REL, pocos ribosomas libres y cuerpos multivesiculares, todas características ultraestructurales de células envueltas en el transporte iónico. La formación de complejos multicelulares sugiere el camino paracelular de secreción de $\mathrm{Na}$. La presencia de uniones celulares posibilita el contacto del retículo con el medio externo. Las células cloro de los teleósteos de agua dulce son más pequeñas, menos columnares, tienen menos pronunciado el sistema tubular y la vía paracelular para el Na está ausente.

Durante el crecimiento se detectan cambios estructurales que consisten en notorio aumento de mitocondrias, oscurecimiento paulatino del citoplasma, anastomosis complejas del sistema tubular relacionado ${ }^{11} \mathrm{y} \mathrm{a}$ su vez, aumento de Na K ATPasa. En la transferencia a aguas salinas la superficie del núcleo se hace irregular, aumenta la electrodensidad de la matriz mitocondrial y se destaca el avanzado desarrollo del Golgi que muestra abundantes y largos sacos con extremos dilatados, desorganizados y desplazados a la región lateral y ba$\mathrm{sal}^{2}$.

Se describe la presencia de criptas apicales, mencionadas como característica distintiva de especies marinas ${ }^{11}$. Acipenser $s p$. presenta células cloro que no muestran criptas pero aparecen cuando los peces son transferidos a agua salada ${ }^{2,17}$. Las criptas apicales constituyen focos de alta conductividad para cationes como el Na que las atraviesan en su pasaje al medio a través de la ruta paracelular y se reporta en este sitio la presencia de mucosustancias polianiónicas que desempeñarían un rol esencial en la concentración de cationes y en el mantenimiento del gradiente de concentración iónica.

\section{TIPOS}

En peces adultos, numerosos trabajos hacen referencia a distintos tipos de células cloro con diferencias morfológicas dependiendo de su localización ${ }^{24}$, sus características apicales ${ }^{14,22}$, por las diferentes densidades eléctricas de su citoplasma ${ }^{26}$ o por la distribución de las proteínas transportadoras de iones ${ }^{9}$. Al parecer, la abundancia relativa de cada tipo celular está relacionada con la composición iónica del medio y la entrada particular de iones.

Asimismo, aumentando el grado de complejidad también se identificaron cambios cronológicos en los 
diferentes estadios de desarrollo. Las denominadas células maduras están en contacto con el agua vía cripta apical, no así las células inmaduras sin cripta ${ }^{13}$. En algunas larvas, el único tipo celular presente tiene baja reactividad al osmio y criptas apicales apenas definidas, en tanto que en juveniles aparecen unas débilmente coloreadas y con débil reacción al osmio, y otras oscuras con fuerte reactividad al osmio.

En Carassius sp. se describen tres tipos de células ricas en mitocondrias, de acuerdo al tamaño de las criptas apicales ${ }^{4}$. La comparación de la relativa abundancia de los diferentes tipos celulares en las diversas especies sugieren que cada tipo podría llevar a cabo funciones distintas, aunque el concepto es cuestionado por diversos autores ${ }^{4}$. Hay células cloro denominadas alfa y otras beta con características opuestas ${ }^{22}$. Se sugirió que la gran variabilidad en la estructura podría representar diferentes momentos del ciclo celular, donde las células oscuras están en un proceso de degeneración apoptótica, pierden contacto con el agua, son más electrodensas y redondeadas, siendo finalmente fagocitadas por macrófagos ${ }^{25}$. Durante la permanencia en aguas ácidas, los estadios de células maduras, inmaduras, accesorias y apoptóticas varían considerablemente.

\section{TAMAÑO Y DENSIDAD}

La mayoría de los trabajos coincide en que las células cloro son más grandes en peces marinos que en los de agua dulce en todas las etapas, pero se menciona a Fundulus heteroclitus como una excepción.

El aumento de tamaño de las células cloro después del pasaje a agua salada fue reportado en el saco vitelino de embriones y larvas y en branquias de adultos de varias especies. En embriones y larvas que permanecen en agua dulce se mantienen hasta la completa reabsorción del saco vitelino, disminuyendo de tamaño paulatinamente con el crecimiento.

No está totalmente claro si las células cloro que existen en agua dulce desaparecen y son reemplazadas con nuevas células cloro diferenciadas al ser transferidos a agua salada o si las células sobreviven e incrementan de tamaño en este medio. Hay trabajos que proveen evidencias directas del turn over, que si bien se observa en células de peces de agua dulce y salada, es aproximadamente tres veces mayor en agua salada ${ }^{26}$.

En el proceso de hipertrofia celular se registra incremento de pliegues en la superficie basolateral coincidente con el aumento del sistema tubular basolateral y el incremento de actividad de la enzima de traslocación proteína $\mathrm{Na} \mathrm{K} \mathrm{ATPasa}{ }^{2,24}$. Tanto la actividad enzimática como las modificaciones morfológicas son consideradas índices de adaptación al agua salada. Llama la atención el efecto del cortisol sobre el tamaño de las células cloro, pero a veces solo se incrementa la densidad celular sin modificarse el tamaño de las mismas. Otras hormonas como la del crecimiento $(\mathrm{GH})$ y el factor de crecimiento insulínico (IGF-1) estimulan el tamaño y número de células cloro.
La proliferación de las células cloro durante la transferencia al agua marina fue referenciado en varios trabajos ${ }^{5,20}$. Algunas veces, el ambiente altera en forma específica a un tipo celular, encontrándose incrementos de la densidad estrechamente ligados a las mejoras de influjo de $\mathrm{Cl}$ y Ca ${ }^{14,16}$. En ocasiones, las diferencias significativas solo aparecen varios días después. Pero algunos hallazgos son contradictorios ${ }^{2,3}$ porque describen la reducción del número total, representando una respuesta atípica. En otros teleósteos, si bien el número aumenta durante los primeros días de adaptación, su apariencia es la de células inmaduras ${ }^{1}$. Por el contrario, la transferencia al agua dulce provoca reducción del número y tamaño celular ${ }^{1}$.

\section{CÉLULAS ACCESORIAS}

El cambio estructural más específico del epitelio branquial durante la aclimatación al agua salada es la aparición de las células accesorias ${ }^{11}$. Concordando con esto, las células accesorias nunca fueron reportadas en peces de agua dulce. Durante el desarrollo ya se pueden formar complejos multicelulares en la membrana del saco vitelino cuando los embriones son transferidos de agua dulce a salada. Cada complejo es considerado como característico de ambientes salinos con función de secreción de iones, principalmente excesos de $\mathrm{Na}$ del fluido corporal que ocurre bajo gradiente electroquímico vía paracelular ${ }^{23}$. Se postula que representan una población de las células cloro parcialmente diferenciada ${ }^{21}$, un tipo celular específico para peces de agua salada ${ }^{12}$.

\section{CONCLUSIONES}

Las células cloro son importantes en la regulación iónica y osmótica no solo en el principio de la vida de los teleósteos sin branquias funcionales, sino que muestran también gran plasticidad para adaptarse al ambiente favoreciendo la supervivencia del pez. Los cambios morfológicos pueden ser rápidos por transformaciones de las células preexistentes o más lentos por reemplazo de nuevas células diferenciadas. El rol en la excreción de $\mathrm{Na}$ y $\mathrm{Cl}$ es indiscutido, sin embargo su rol en la absorción de estos iones continua siendo controvertido pues se están reuniendo evidencias que el sitio de ingreso de $\mathrm{Na}$ son las células pavimentosas, antes que las células cloro.

\section{REFERENCIAS}

1. Altinok I, Galli S, Chapman F. 1998. Ionic and osmotic regulation capabilities of juvenile Gulf of Mexico sturgeon, Acipenser oxyrinchus de sotoi. Comp Biochem Phys A 120: 609-616.

2. Carmona R, García-Gallego M, Sanz A, Domezain A, Ostos Garrido M. 2004. Chloride cells and pavement cells in gill epithelia of Acipenser naccarii: ultrastructural 
modifications in seawater-aclimated specimens. J Fish Biol 64: 553-566.

3. Cataldi E, Ciccotti E, Di Marco P, Di Santo O, Bronzi P, Cataudella S. 1995. Acclimation trials of juvenile italian sturgeon to different salinites: morpho-physiological descriptor. J Fish Biol 47: 609-618.

4. Chang I, Lee T, Wu H, Hwang P. 2002. Effects of environmental $\mathrm{Cl}$ - levels on $\mathrm{Cl}$ uptake and mitochondria-rich cell morphology in gills of the stenohaline goldfish, Carassius auratus. Zool St 41: 236-246.

5. Cioni C, De Merich D, Cataldi E, Cataudella S. 1991. Fine structure of chloride cells in freshwater and seawater adapted Oreochromis niloticus (Linnaeus) and Oreochromis mossambicus (Peters) J Fish Biol 39: 197-209.

6. Evans D. 2002. Cell signaling and ion transport across the fish gill epithelium. J Exp Zool 293: 336-347.

7. Henderson V. 1995. Relationship of the tubular system with other organelles in chloride cells of the channel catfish, Ictalurus punctatus. J Morphol 224: 31-45.

8. Hiroi J, McCormick S, Ohtani-Kaneko R, Kaneko T. 2005. Functional classification of mitochondrion-rich cells in euryhaline Mozambique tilapia (Oreochromis mossambicus) embryos, by means of triple immunofluorescence staining for $\mathrm{Na} / \mathrm{K}$-ATPase, $\mathrm{Na} / \mathrm{K} / 2 \mathrm{Cl}$ cotransporter and CFTR anion channel. J Exp Biol 208: 2023-2036.

9. Hiroi J, Miyazaki H, Kataoh F, Ohtani-Kaneko R, Kaneko T. 2005. Chloride turnover and ion-transporting activities of yolk- sac preparations (yolk balls) separated from Mozambique tilapia embryos and incubated in freshwater and seawater. J Exp Biol 8: 3851-3858.

10. Kaneko T, Shiraishi K., Katoh F, Hasegawa S. 2002. Chloride cells in early life stages of fish and their functional differentiation. Fish Sci 68: 1-9.

11. Laurent P. 1984. Gill internal morphology. In: Fish Physiology (Hoar W, Randall D. Eds.), Academic Press, Orlando (USA), p. 73-84.

12. Laurent P, Perry S. 1990. The effects of cortisol in gill chloride cell morphology and ionic uptake on the freshwater trout, Salmo gairdneri. Cell Tissue Res 259: 429-442.

13. Li L, Eygensteyn J, Lock R, Verbost P, Van Der Heijden A, Wendelaar Bonga S, Flick G. 1995. Branchial chloride cells in larvae and juveniles of freshwater tilapia Oreochromis mossambicus. J Exp Biol 198: 2177-2184.

14. Lin L; Hwang P. 2004. Mitochondria-rich cell activity in the yolk-sac membrane of tilapia (Oreochromis mossambicus) larvae acclimatized to different ambient chloride levels. J Exp Biol 207: 1335-1344.
15. Marshall W. 1995. Transport processes in isolated teleost epithelio: opercular epithelium and urinary bladder. In: Fish Physiology (Woods S. Ed.), Academic Press, San Diego (USA), p. 1-23.

16. McCormick S, Hasegawa S; Hirano T. 1992. Calcium uptake in the skin of a freshwater teleost. Proc Natl Acad Sci 89: 3635-3638.

17. Mc Cormick S. 2001. Endocrine control of osmoregulation in teleost fish. Am Zool 41: 781-794.

18. Morgan I, Potts W. 1995. The effects of the adrenoreceptor agonist phenylephrine and isoproterenol on the intracellular ion concentration of branchial ephitelial cells of brown trout (Salmo trutta L). J Comp Physiol 165: 458-463.

19. Perry S, Goss G, Laurent P. 1992. The interrelationships between gill chloride cell morphology and ionic uptake in four freshwater teleost. Can J Zool 70: 1775-1786.

20. Perry S. 1997. The chloride cell structure and function in the gill of freshwater fishes. Ann Rev Physiol 59: 325-347.

21. Pisam M. 1981. Membranous systems in the chloride cell of teleostean fish gill, their modifications in response to the salinity of the environment. Anat Rec 200: 401-414.

22. Pisam M, Caroff A, Rambourg A. 1987. Two types of chloride cells in the gill epithelium of a freshwater-adapted euryhaline fish: Lebistes reticulatus, their modifications during adaptation to saltwater. Am J Anat 179: 40-50.

23. Silva P, Solomon R, Spokes K, Epstein F. 1977. Ouabain inhibition of gill Na-K-ATPase: relationship to active chloride transport. J Exp Zool 199: 419-426.

24. Uchida K, Kaneko T, Yamauchi K, Hirano T. 1996. Morphometrical analysis of chloride activity in the gill filaments and lamellae and changes in $\mathrm{Na}, \mathrm{K}$, ATPase activity during seawater adaptation in chum salmon fry. $J$ Exp Zool 276: 193-200.

25. Wendeelar Bonga S, Van der Meij J. 1989. Degeneration and death, by apoptosis and necrosis, of the pavement and chloride cells in the gills of the teleost Orechromis mossambicus . Cell Tissue Res 255: 235-243.

26. Wendeelar Bonga S, Flick G, Balm P, Van der Meij J. 1990. The ultrastructure of chloride cells in the gills of the teleost Oreochromis mossambicus during exposure to acidified water. Cell Tissue Res 259: 575-585.

27. Zaccone G, Licata A. 1981. Histochemistry and fine structure of the flamecone cells in the skin epidermis of the sea horse fish Hippocampus ramulosus Leach 1814 (Teleostei: Syngnathidae). Arch Biol (Bruxelles) 93: 249-266. 